\title{
Agôn
}

Critiques | Saison 2013-2014

\section{Swamp Club, conception et mise en scène de Philippe Quesne}

Ambiguë métaphore

\section{Caroline Châtelet}

\section{(2) OpenEdition}

Journals

Édition électronique

URL : https://journals.openedition.org/agon/2706

DOI : 10.4000/agon.2706

ISSN : 1961-8581

Éditeur

Association Agôn

Référence électronique

Caroline Châtelet, "Swamp Club, conception et mise en scène de Philippe Quesne », Agôn [En ligne],

Critiques, mis en ligne le 20 août 2013, consulté le 08 décembre 2022. URL : http://

journals.openedition.org/agon/2706; DOI : https://doi.org/10.4000/agon.2706

Ce document a été généré automatiquement le 29 septembre 2020.

Tous droits réservés 


\title{
Swamp Club, conception et mise en scène de Philippe Quesne
}

\author{
Ambiguë métaphore
}

Caroline Châtelet

\section{RÉFÉRENCE}

Swamp Club - conception, mise en scène et scénographie Philippe Quesne Salle de spectacle de Védène, Festival In d'Avignon, du 17 au 24 juillet 2013 www.festival-avignon.com / www.vivariumstudio.net Les dates à venir : du 30 au 31 août à La Bâtie Festival de Genève ; le 8 septembre au Festival Homo Novus à Riga (Lettonie) ; les 25 et 26 septembre à L'Arsenic à Lausanne ; du 7 au 17 novembre au Théâtre de Gennevilliers dans le cadre du Festival d'Automne à Paris; les 21 et 22 novembre au Forum Scène conventionnée du Blanc-Mesnil dans le cadre du Festival d'Automne à Paris ; les 29 et 30 novembre au Spielart Festival à Munich ; les 10 et 11 décembre au Théâtre Universitaire La Vignette à Montpellier ; le 21 janvier 2014 au Centre Culturel Agora à Boulazac ; le 24 janvier au Carré - Les Colonnes Scène conventionnée de Saint-Médard-en-Jalles ; le 28 janvier au Parvis Scène nationale de Tarbes-Pyrénées ; les 21 et 22 février au Kaaitheater à Bruxelles ; les 6 et 7 mai à La Comédie de Reims; les 14 et 15 mai au Maillon Théâtre de Strasbourg; les 21 et 22 mai à La Filature Scène nationale de Mulhouse ; en juin 2014 au Festival Theaterformen d'Hanovre et en novembre au Tokyo Festival.

1 Voilà dix années que le metteur en scène et scénographe Philippe Quesne a monté sa compagnie, Vivarium Studio. Au sein de celle-ci, et avec une équipe réunissant notamment acteurs, musiciens et plasticiens, Quesne a creusé son sillon, construisant à travers ses créations des univers propres que les spectateurs seraient invités à observer comme devant un vivarium. Spécificité - parmi d'autres - du Vivarium Studio: l'enchaînement des spectacles fonctionne comme un jeu de kyrielles (telle la comptine «trois petits chats ») et la dernière image de la précédente création nourrit toujours 
celle à venir, chacune s'inscrivant dans un continuum. Ainsi, le précédent opus Bing Bang se terminant (plus ou moins) les pieds dans l'eau, c'est dans un marécage que se situe Swamp Club. Ce "club», c'est un lieu de résidence pour artistes, français et étrangers, bâtiment sur pilotis installé sur un marais et situé à proximité d'une grotte. Tandis que des artistes y sont déjà, parmi lesquels le quatuor Odéon qui jouera une partie du spectacle, de nouveaux résidents sont attendus. Une fois les préparatifs pour leur arrivée terminés, les artistes accueillis, la visite des lieux effectuée, un événement vient troubler l'apparente quiétude. Aux nappes de mélancolie succède une atmosphère plus lourde, tendue, et les résidents vont mettre en place diverses procédures, destinées à préserver ce fragile univers. Toutes se révéleront infructueuses, contraignant les artistes à se réfugier (disparaître?) dans la grotte. On voit ici la métaphore, assez terrible par ailleurs par sa possible réalité, d'un univers artistique coupé du monde - ou « sur » ce monde, marais croupissant -, installé en vase clos dans ses propres logiques, menacé d'un danger imminent, mais incapable d'y faire face et contraint à la fuite. Les protagonistes de ce club évoluent dans un univers à la temporalité autre et le jeu, les déplacements, les actions se font dans une lenteur volontaire, proche du quotidien. Cet enchaînement d'atmosphères et d'ambiances se déroule patiemment et la beauté formelle dénuée de tout spectaculaire, sans clinquant, résonne bien avec l'idée de vivarium: le spectateur observe ici un microcosme, sans que ce fragile éco-système ne soit affecté de sa présence. Déjouant toute attente de la part du spectateur, cette temporalité volontairement déceptive peut parfois être déstabilisante, d'autant qu'elle s'accompagne d'un humour tenace né du dérisoire, de l'absurde - telle cette présence d'une taupe géante - voire d'un décalage entre prosaïsme des gestes et maîtrise des images. Mais quoique tout cela soit cohérent, construit, tenu, ce Swamp Club laisse, au final, totalement indifférent. Et la langueur de l'ensemble, plutôt que d'être naturelle ou évidente, devient ici singulièrement forcée et pesante. Comme si la tension, l'absence d'énergie, l'air vicié du marais sur lequel sont installés ces artistes avaient contaminé et pourri la forme. Au sortir de ce spectacle, difficile de savoir qui a produit quoi : ce déploiement jusqu'à l'ennui est-il le résultat de la métaphore portée par ce club, où est-ce le mode de travail de Philippe Quesne qui peine à se renouveler et en vient à produire cet étirement profondément assommant ? 
Swamp club

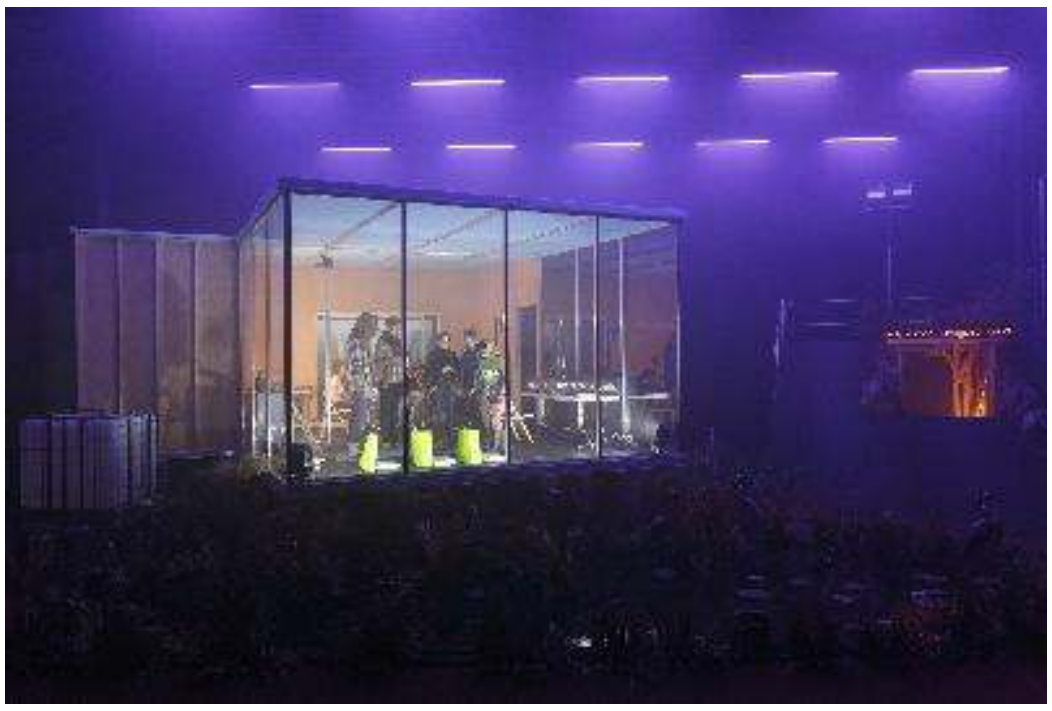

(c) Christophe Raynaud de Lage / Festival d'Avignon 